$154-(220)$

\section{S - 5 THE EXPERIENCES OF RECTOSIGMOID POUCH AS A CONTINENT URINARY DIVERSION AFTER RADICAL CYSTECTOMY}

\author{
江博缷，员文正．江金培 \\ 高雄藇掌院 泌尿科。高雄。台溇。
}

Thirty-five patients receiving cystectomy underwent rectosigmoid pouch. The technique of ureteral submucous implantation was described. The follow-up results were analyzed. The relationship of postoperative voiding frequency and preoperative anal closure pressure was assessed. The day and night time continence rate is $97 \%$ (34/35). There were no hydronephrosis, no ureterocolonic stricture or reflux. The complications are not unique to rectosigmoid pouch and not high when compared with other forms of urinary diversion. When the preoperative anal closure pressure reaches nearly $100 \mathrm{cmH}_{2} \mathrm{O}$ a postoperative outcome with good quality of life will be predicted. With the advantages of high continence rate and simr .city of performance the rectosigmoid pouch will become one of the alternative forms of continent urinary diversion. For obtaining the favorable results a patient with normal renal function, good hepatic function and anal closure pressure more than $50 \mathrm{cmH}_{2} \mathrm{O}$ is required.

\section{S - 6 The Multifocal Urothelial Cancers can be Arisen from Independent Clonal Origin}

Chun-Nung Huang, Kou-Wha Kuo*, Yen-Hwang Chuang**, Wen-Jeng Wu and Chun-Hsiung Huang

Department of Urology, Department of Biochemistry*, and Department of Anatomy**

Kaohsiung Medical College, Kaohsiung, Taiwan

To investigate the clonal origin of multifocal urothelial tumors, the chromosomal DNA pattern, and the protein expression of p53 and retinoblastoma $(\mathrm{Rb})$ in the urothelial cancers were determined by differential display PCR and immunohistochemistry, respectively. The expressions of p53 and $\mathrm{Rb}$ in all the examined bladder tumors revealed the same quantity of protein expressions. The concordance of chromosomal DNA patterns was observed in most synchronous and metachronous tumors. However, a case with contralateral renal pelvis tumor following the bladder tumor displayed the different DNA patterns in most of the primers examined. Since synchronous and metachronous urothelial tumors are characterized by multifocus originated from the same progenitor cell, the present communication evidences that urothelial cancer can be arisen from different clonal origins

\section{I - 7 The Use of Intravesical Bacilli Calmette-Guérin In Patients with Superfical Bladder Tumors and Urothelial Atypia}

Ming-Yang Huang, M.D.

Department of Urology, Provincial Taichung Hospital, Taichung, Taiwan

Various strains of BCG have been reported to be equally effective or superior to chemotherapy. The role of BCG as prophylaxis against recurrence of Stage O-A bladder tumors, in the treatment of existing superficial bladder tumors, and in the treatment of moderate or severe urothelial atypia were evaluated in this study. Tice strain BCG ( 1 vial, $2-8 \times 10^{8}$ organisms, in $60 \mathrm{cc}$ saline) was used intravesically without cutaneous inoculation. Group I-22 patients with tumors recurrence were treated prophylaxisly once weekly for six weeks followed by once monthly for 12 months or until recurrence. Group II-22 patients with existing Stage O-A TCC and Group III-19 patients with moderate or severe urothelial atypia received 8 weekly instillations followed by instillations once monthly for 12 months or until failure $67 \%$ of patients have no recurrence in group I from 10-26 months ( $M=15$ mos). $36 \%$ of patients in group II had complete regression following BCG therapy and $23 \%$ had a partial response from 10-18 months ( $M=13$ mos). $68 \%$ of paitents in group III had complete response and $16 \%$ were markedly improved and no recurrence was occurred from 11-20 months ( $M=14.5$ mos). Tice strain $B C G$ is effective as a prophylaxis against recurrence of superficial bladder tumors and in the treatment of urothelial atypia.

\section{| $S$ - 8 Mutation Analysis of Renal Cell}

KENYA YAMAGUCHI, KENJI CHINO, YUICHI KISHIMOTO, HAJIME ISHIDA AND KIYOKI OKADA

Department of Urology, Nihon university, Tokyo, Japan.

BACKGROU N D From 1990 to date, many reports Indicated that deletions in chromosome $3 p$ are responsible for tumorigenesis of renal cell carcinoma(RCC). We also have been conducting mutation analysis of RCC from 1991. Herein, we report the results of our investigation about deletion, mutation and replication errors in surgical specimens of RCC.

METHODS Palred (tumor and normal tissue) genomic DNA samples were extracted from 33 surgical specimens. To detect LOH(loss of heterozygosity) in chromosome 3p. 15RFLP (restriction fragment length polymorphism) markers were used for southern blot hybridization. To detect mutation in p53gene, PCR-SSCP(polymerase chain reaction single strand conformation polymorphism) were performed. To detect DNA replication error (RER), six microsatellite markers from five chromosomes were employed.

RESULTS 1. LOH in chromosome $3 p$ was most frequently found when examined by PCR-RFLP with a probe Acc1 $(8 / 15 ; 53.3 \%)$.

2. No cases showed $\mathrm{p} 53$ gene mutation at exons $5,6,7,8,9$, in 30 cases.

3. No cases showed RER in 33 cases.

CONCLUSION These results supported the significance of deletion in chromosome $3 \mathrm{p}$ but did not confirm participation of p 53 gene mutation or RER for tumorigenesis of RCC. 